Rhode Island College

Digital Commons @ RIC

\title{
Increasing Nurses' Knowledge and Confidence Using the Teach- back Method to Teach Fall Prevention Strategies to Residents in Long Term Care
}

Christine Nichols

Follow this and additional works at: https://digitalcommons.ric.edu/etd

Part of the Nursing Commons

\section{Recommended Citation}

Nichols, Christine, "Increasing Nurses' Knowledge and Confidence Using the Teach-back Method to Teach Fall Prevention Strategies to Residents in Long Term Care" (2018). Master's Theses, Dissertations, Graduate Research and Major Papers Overview. 269.

https://digitalcommons.ric.edu/etd/269

This Major Paper is brought to you for free and open access by the Master's Theses, Dissertations, Graduate Research and Major Papers at Digital Commons @ RIC. It has been accepted for inclusion in Master's Theses, Dissertations, Graduate Research and Major Papers Overview by an authorized administrator of Digital Commons @ RIC. For more information, please contact digitalcommons@ric.edu. 
INCREASING NURSES' KNOWLEDGE AND CONFIDENCE USING THE TEACHBACK METHOD TO TEACH FALL PREVENTION STRATEGIES TO

\section{RESIDENTS IN LONG TERM CARE}

\section{by}

Christine Y. Nichols

A Major Paper Submitted in Partial Fulfillment

of the Requirements for the Degree of

Master of Science in Nursing

in

The School of Nursing

Rhode Island College

2018 



\begin{abstract}
Fall prevention in health care settings, either acute care or long-term care, has been identified as an area of focus for quality improvement. The Joint Commission and the Centers for Medicare and Medicaid have developed goals and recommendations for all areas of health care to follow to decrease falls and improve patient and resident quality of life. Direct care nurses are relied upon to provide the education and to assist in preventing falls, but often do not measure the retention of the information provided. The purpose of this quality improvement project was to provide education on the teach-back method to nurses working in a small, family owned long-term care facility. Benner's skills acquisition theory and Kellogg's Logic Model were used as the theoretical framework for developing the project and education. The aim was to increase knowledge and confidence using the teach-back method. An educational program was developed to provide education to the nurses. The education was followed by the opportunity to practice using the teach-back method in a role-playing scenario. Pre and post education tests were provided to determine if the education increased the nurses' knowledge of the method. Thirty-three percent $(\mathrm{N}=10)$ of the nurses employed at the facility participated. Prior to the education, $40 \%(n=4)$ of the participants felt the teach-back method was not a practical method for teaching fall prevention strategies to the residents, as compared to $80 \%(\mathrm{n}=8)$ in the post test. With a greater focus by regulatory agencies on fall prevention programs in long-term care settings, the advanced practice registered nurse can take on the role of leader in guiding nurses through the process of improving education and resident outcomes.
\end{abstract}




\section{Acknowledgements}

I'd like to begin by thanking Dr. Cindy Padula, my first reader, who kept me focused and on track throughout the process of writing this paper. I'd also like to thank Dr. Marie Wilks and Kathy Bergeron, my second and third readers respectively. Your input was valuable, and I appreciate the time you spent reading and reviewing my paper.

I'd like to thank Patti Calvert, who has been my advisor through my time in school. Your knowledge and support has meant a lot to me. I would not have made it this far without your help.

Thank you does not seem to be enough for my husband Brian and my daughters Kelsey and Megan. Thank you for understanding when I couldn't be somewhere or help with homework because I was doing mine. Without your support through this, I would not have made it to where I am today. To my mom, thank you for all your support during this process. Dad, when I started on this journey, you were here with me, losing you was one of the most difficult things to get through. I know you'll be with me when I walk across that stage,

Lastly, I'd like to thank the friends I've made on this journey. You are an exceptional group of individuals who I am honored to know. May you all prosper in your careers. 


\section{Table of Contents}

Background/Statement of the Problem........................................ 1

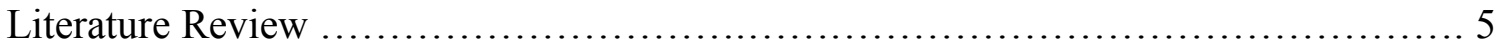

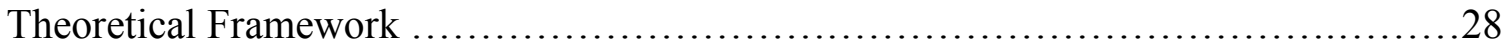

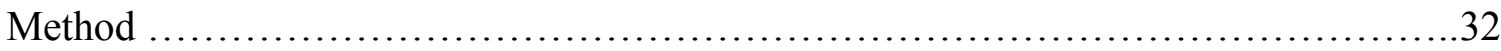

Results.................................................................... 38

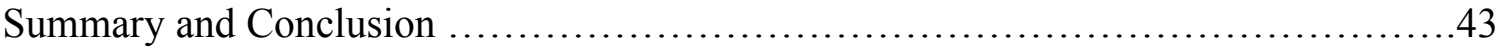

Recommendations and Implications for Advanced Nursing Practice .................46

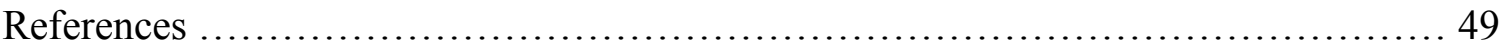

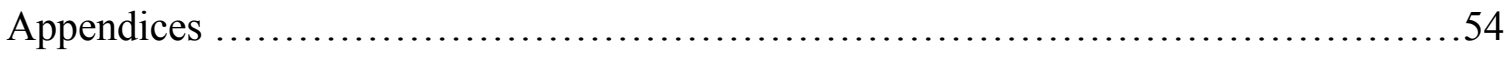


Increasing Nurses’ Knowledge and Confidence Using the Teach-Back Method to Teach Fall Prevention Strategies to Residents in Long Term Care

\section{Background/Statement of the Problem}

A manual to guide the development of fall management programs for nursing facilities demonstrated the impact falls have on residents in long-term care/post-acute facilities (Taylor, Parmelee, Brown \& Ouslander, 2005). The development of the manual was supported by the Agency for Health Research and Quality (AHRQ). The first chapter points out that of the 1.6 million Americans who reside in nursing homes, approximately half fall annually and 1 in 3 residents fall at least twice in a year (Taylor et al.). Falls in the frail elderly often have consequences that impact their quality of life. Post fall, many fall at least twice in a year (Taylor et al.). Post fall, many residents develop an enhanced fear of falling that can lead to self-imposed limitations on activity. Many long-term care nursing facilities have fall prevention programs in place but recognize there is always room for improvement (Taylor et al.).

The National Data Base of Nursing Quality Indicators (NDNQI) defines a fall as "an unplanned, either assisted or unassisted, descent to the floor with or without injury to the patient" (NDNQI as cited in Staggs et al., 2015). This includes falls "when a patient lands on a surface where you would not expect to find a patient" and includes all falls, whether they result from a physiologic or environmental reason (NDNQI as cited in Staggs et al., 2015). Reduction of falls in the hospitalized adult medical or surgical patient was identified by the Joint Commission in 2009 as a national patient safety goal (Joint Commission, 2017). The 2018 National Patient Safety Goals put forth by the Joint Commission for nursing care centers included a goal to reduce the risk of patient and 
resident harm resulting from falls. The elements of the goal focused on risk assessment and education for the resident and their families (Joint Commission, 2018).

Many hospitals have implemented fall prevention programs to reduce incidence of falls in their facilities (Cangany M., Back, D., Hamilton-Kelly, T., Altman, M., \& Lacey, S., 2015; Quigley, P. A., Barnett, S. D., Bulat, T., \& Friedman, Y., 2016; Urquhart Wilbert, 2013). Research on fall prevention strategies in long-term care has been limited. Studies by Neyens et al. (2008) and Rapp et al. (2009) both studied nursing homes outside of the United States to determine what fall prevention programs worked well in the long-term care setting. There were no current studies performed on fall prevention in long term care facilities in the United States. Patient and family education on identifying fall risks and fall prevention strategies is a component of most fall prevention programs (Cangany et al., 2015). The majority of these programs rely on the bedside nurse to provide written and/or verbal education to the patient and family on fall risk and fall prevention. Fall prevention education has traditionally consisted of a pamphlet or printed handout given to the patient identified by an evidence-based risk assessment tool as a fall risk (Cangany et al.). The information is provided to the patient with the understanding that it will be read and understood. However, this method is not a reliable way to ensure that the patient/family has received and understood the information (Cangany et al.). It may not take into account the non-English speaking patient or the patient who is unable to read the material due to visual problems or inability to read at the grade level of the materials. In contrast, fall prevention programs may include patient return demonstration of skills such as proper use of the nurse call light to reinforce the education (Urquhart Wilbert, 2013). 
The teach-back method is an evidence-based method that confirms patient understanding of materials taught to them by a health care professional (Tamura-Lis, 2013). The objective is to have the patient relay back to the health care professional what has been retained, in their own words. This allows the individual providing the education to assess what the patient has learned and what needs to be reinforced in later education sessions (Tamura-Lis). Since the early 2000s, the teach-back method has become standard practice for nurses to assess whether information they are providing to patients has been understood and retained (Brady, 2013; Caplin \& Saunders, 2015; Miller, 2016). The question arises: How confident are the nurses using the teach-back method?

Nurses receive instruction on patient and family education in a variety of ways. Some hospitals provide classroom in-service education programs to staff, which may not be required or well attended. Other facilities may rely on web-based learning modules as a part of orientation to the facility or as part of annual competency training. Teaching and assessing a topic that is more conceptual may leave nurses unsure of how to assess a patient's and/or family's level of understanding of the material. It is important to have a reliable method to assess comprehension of patient/family education. Often, patients are reluctant to admit they did not understand or fully grasp important information provided verbally or in writing (Caplin \& Saunders, 2015). Since fall prevention education is not skill-based education, nurses may feel that the teach-back method is not appropriate for them to utilize and therefore do not use this method to assess the comprehension and retention of this material.

There is no current research related to use of the teach-back method with residents in long term care facilities. The teach-back method is commonly used in acute care 
hospitals to teach discharge instructions and to ascertain whether the material has been understood. While discharges do occur in long term care facilities, the numbers are much smaller than what occurs in acute care facilities. There is potential, however, to use the teach-back method for those residing in the facility, as well as their family members, to teach fall prevention strategies. Nurses working in a small, family owned long-term care facility receive no instruction on the teach-back method during orientation or during annual competencies. The only exposure to the teach-back method would have been in nursing school and many of the nursing staff has been out of the academic setting for many years. These are missed opportunities that contribute to the high fall rates of residents in long term care

The purpose of this quality improvement project is to increase nurses' knowledge and confidence using the teach-back method to teach fall prevention strategies to residents in long-term care.

Next, the review of the literature will be presented. 


\section{Literature Review}

A review of current nursing literature was conducted utilizing CINAHL and EBSCO. Keywords searched included hospital falls definition, fall prevention programs, fall prevention in long term care, health literacy and nursing knowledge and confidence using the teach back method. Research articles published greater than 12 years ago were not considered for this literature review.

\section{Falls: Definition}

The definition of a fall that will be used to guide this project is the current NDNQI definition. NDNQI as cited in Stagg et al. 2015, defines a fall as "an unplanned, either assisted or unassisted, descent to the floor with or without injury to the patient." This includes falls when a patient lands on a surface where one would not expect to find a patient and includes all types of falls, whether they result from a physiologic (syncopal event) or environmental reason (tripping on equipment) (NDNQI as cited in Stagg et al., 2015).

The National Quality Forum website (2016) defines a fall as "a sudden, unintentional change in position causing an individual to land on a lower level, on an object, the floor or the ground." Rubenstein (2006) described a fall as an event that "is associated with one or more identifiable risk factors, including weakness, unsteady gait, confusion or certain medications" (p. 37).

Falls arise from multiple factors, including impaired cognition, mobility, gait and balance (Tzeng \& Yin, 2015). Falls can impact length of stay, morbidity and mortality, as well as hospital reimbursement from insurance companies for an injury resulting from a fall during hospitalization (Tzeng \& Yin). Hospitalized patients are at a greater risk for 
falling than the general population, not just due to the reasons listed but also from medications used for sedation and pain relief and mental status changes from medications or from the illness itself. In 2007, patients who sustained an injury with fall had an average hospital stay of 6.3 days longer than other patients with the same or similar diagnoses who had not fallen (Tzeng \& Yin). This increased length of stay translated to $\$ 13,000$ more in medical related cost in 2007 dollars. This additional cost may or may not be reimbursed. In fiscal year 2009, the Centers for Medicare and Medicaid (CMS) ended payment for treating certain preventable inpatient injuries, this included injuries resulting from inpatient falls (CMS, $2016 \mathrm{a}$; Tzeng \& Yin, 2015). Beginning in fiscal year 2015, CMS implemented a 1\% deduction in total Medicare payments for hospitals scoring in the top quartile for harmful events occurring to patients during hospitalization (CMS, 2016 a). Creating meaningful and sustainable fall prevention programs became a focus for hospitals to decrease the financial impact of the CMS payment guidelines.

The definition of a fall in long-term care uses the same principles and wording as the NDNQI definition of a fall. Robinovich et al. defined a fall in long-term care as "an unintentional coming to rest on the ground, floor, or other lower level" (2013, p.49). In 2016, CMS instituted a reporting structure for long-term care facilities to report falls with major injury in their long-term residents. CMS defined a major injury as "bone fractures, joint dislocations, closed head injuries with altered consciousness or subdural hematoma" (2016 b).

\section{Falls: Incidence}

Falls are a significant cause of preventable injury and death, particularly in the elderly (Urquhart Wilbert, 2013). Tzeng \& Yin (2015) emphasized that falls can arise 
from multiple factors including impaired cognition, impaired mobility, unsteady gait, balance disturbances and a history of falling. Falls that occur in the community setting are one of the leading causes for hospital and subsequent long-term care admissions in the older adult (Urquhart Wilbert, 2013).

Despite the growing numbers of falls that occur, few studies have been conducted that focus on fall prevention strategies in long-term care facilities (Robinovitch et al. 2013). Nationally, the average percentage of falls without injury in an averaged sized nursing home (100-150 beds) was $11 \%$ in 2014 . The percentage of falls with injury for the same sized home was 5.3\% (CMS, 2016b).

\section{Fall prevention programs}

Fall prevention programs, designed to identify patients at risk for falls, offer suggested fall prevention strategies and reassess the process when a fall has occurred, are common practice in hospitals (Cangany et al., 2015; Quigley et al., 2016; Tzeng \& Yin, 2015). The fall prevention programs often utilize an evidence-based assessment tool, such as the Morse Tool or the Johns Hopkins Fall Risk Assessment Tool. Once a patient's risk has been identified, the majority of fall prevention programs offer interventions to the staff to mitigate the risk. Fall risk signage, colored bracelets, colored non-slip socks, and bed/chair alarms are just a few of the many interventions that fall prevention programs utilize (Cangany et al.; Quigley et al.; Tzeng \& Yin). The Institute

for Health Improvement (IHI, 2017) website reinforces the findings discussed in multiple research articles that a successful fall prevention program includes identifying patients at high risk for falling, multifactorial assessments and interventions. The interventions should include preventive action to modify and compensate for risk factors. Many 
interventions require multidisciplinary support and that patient safety programs are in place across all settings of care (IHI). Patient and family education have also been identified as crucial components of fall prevention programs (Quigley et al., 2016).

Tzeng and Yin (2014) examined the most helpful and least helpful aspects of fall prevention education using a survey of nurses. The study was conducted at five nonprofit health care systems in the Midwest over an eight-month period and included nurses from a variety of practice settings. If the participants met the inclusion criteria of being over 21 , employed as a staff nurse on one of the study units for at least 12 months, provided direct patient care for at least 20 hours per week, and had current licensure in the state, they were eligible to be included in the survey. There were 2170 nurses that met the criteria to participate in the survey and of those, 560 submitted a completed survey. The respondents were further broken down by the type of unit worked on.

The survey, developed and validated by the authors, was divided into three sections each looking at different aspects of fall prevention: fall risk factors; fall prevention interventions: and injurious fall. The first section listed 81 potential risk factors that could lead to falls with injury in the hospitalized adult patient. The second section provided 75 interventions available for preventing falls. Section three included 12 optional items and two open ended questions related to injurious fall prevention (Tzeng \& Yin).

The authors concluded that certain fall prevention interventions, such as applying fall risk identifiers (yellow wrist identification bands, socks, and signs on high risk fall patient doors), bathroom safety, and call light within reach, were identified by the participants as the most effective measures. The data was presented in a table, with the 
most effective measures identified listed at the top. Of the 560 participants, 465 stated that they had received fall prevention education within the past 12 months (Tzeng \& Yin). The authors acknowledged a low responses rate (Tzeng \& Yin).

\section{Hospital-Based Falls Prevention Research}

In a retrospective medical record review by Urquhart Wilbert (2013), electronic medical records were reviewed to determine if patients were identified as a fall risk and if fall prevention interventions were implemented. The sample was comprised of patients greater than 70 years of age who had fallen in a rural VA Medical Center. The study was conducted one year after implementation of the fall prevention program at the medical center. The medical center staffs were educated on fall risk identification, factors that could trigger increased fall risk, and interventions available to prevent or reduce a fall from occurring. One hundred forty medical records were reviewed of patients who had been admitted to the 40-bed study unit one year after implementation of the fall prevention program.

Some of the common measures implemented to reduce or prevent a fall that were documented in the medical records included keeping the patient's bed in low position, non-skid footwear, positioning the patient near the nurses' station, and the use of bed/chair alarms. No direct correlation was found between fall prevention program implementation and the fall rate and all events did not decrease. However, the study did reveal that $56 \%$ of the patients were prescribed psychotropic medications. There was no further discussion related to medications published in the study. (Urquhart Wilbert).

Trepanier and Hilsenbeck (2014) discussed an approach to decreasing falls with injury and its associated cost. A team was brought together to develop a process to 
decrease the anticipated number of falls. The study took place in a for-profit health care system based in the Midwest United States which owned and operated 50 hospitals in 11 states. The authors examined the use of an interdisciplinary team approach to fall prevention. A variety of fall prevention strategies were developed including educational materials for patients and their families. Once a patient was identified as a fall risk, the health care team would develop an individualized plan of care to mitigate the risk of the patient falling. Since each plan of care was individualized based on the specific patient's fall risk, the interventions were not uniform for all patients. The program was deployed over a period of four months in an attempt to decrease the anticipated number of falls. A 12-month retrospective analysis of raw data was then reviewed. Post implementation falls decreased by $41 \%$ in the first year and an additional $31 \%$ the second year. Prior to implementation of the program, the average number of falls in the previous 12 months was 61. The first year after program implementation, the number of falls reported was 36 , by the second year; the number had decreased to 25 , this would then translate into cost savings by reducing the projected cost associated with a fall event (Trepanier \& Hilsenbeck).

Cangany et al. (2015) examined an evidence-based approach for fall prevention with the bedside nurse as the lead educator for the patient population. The purpose of the project, which took place on a 30-bed medical progressive care unit, was to increase nurses' knowledge of the current fall prevention policy and implement a patient safety contract with the patients. The goal was to decrease the overall number of falls by $50 \%$ within a one-year period. The authors used the NDNQI definition of a fall and calculated fall rate based on 1000 patient days. As part of their action plan, a 40-minute staff 
education video was produced based on actual fall events that had occurred in the hospital which all staff on the unit viewed. The remainder of the one-hour in-service was used to educate staff on the fall prevention education that had been developed, including documentation requirements, the Morse fall risk assessment tool, and patient/family education. Interventions that were reviewed during the educational sessions included the patient safety contract and the use of fall signage. The fall signage, designed to serve as a reminder to patients to call for assistance before getting out of bed, was placed on the ceiling above the patients' bed. Patient record audits were performed after the education was completed and the program was implemented. A total of 246 audits were completed, evaluating five outcomes: was the Morse fall risk assessment scale completed; was the fall risk score assigned and was the patient considered a risk for falling; were fall prevention interventions implemented; was the fall prevention care plan in place; and was the patient safety contract completed.

The total number of falls decreased by $50 \%$ over a two-year period and fell below the NDNQI benchmark used to measure progress toward the goals established at the beginning of the project. The reported fall rate prior to the project was 37 . Two years later the fall rate was reported as 11 . Cangany et al. discussed the clinical implications of focusing on two specific interventions-the patient safety agreement and room signage indicating the patient is a fall risk. The sustainability plan was to continue to track and report fall rates and safety contract/signage audits quarterly to unit and hospital nurse leadership to maintain momentum for the project.

Coyle (2016) studied initiating and sustaining a fall prevention program at a 188bed community hospital in New Jersey. The author used the DMAIC (define, measure, 
analyze, improve and control) Six Sigma methodology for program development. Working with the fall prevention committee during the initial phase of the project, the author found that multiple fall prevention programs had been introduced in the hospital, but none were sustained. The fall prevention committee reviewed post fall data from occurrence reports and medical chart reviews looking for fall prevention interventions that were in place prior to the fall. The committee also assessed availability of needed equipment such as bed alarms on individual units. Work sessions with the fall prevention committee identified factors that led to falls and common themes such as elimination/bathroom needs, medications, environmental issues, physical ability/mobility, mentation/cognition, and current diagnosis. Subcategories such as urinary urgency, opioid use, clutter, muscle weakness, confusion, and stroke were placed under the main risk factor that they were directly related to.

An evidence-based bundle approach was developed to promote identified patient safety best practices. The fall bundle included bed and chair alarms for high risk patients, remaining with high risk fall patents while they're being toileted, hourly rounding, diversion activities for confused, high risk patients, standard communication aids, and initiation of post fall debriefings. One-year post-implementation of the fall bundle, the hospitals fall rate decreased from 3.69 per 1000 patient days to 1.69 per 1000 patient days. In addition, there was a noted improvement in the culture of safety surrounding fall prevention. Staff now recognize that everyone is responsible to keep patients safe, they pay more attention to bed alarms, and ancillary staff (transport, dietary, etc.) are responding to bed/chair alarms as well (Coyle). 
A one-year multihospital falls collaborative in six Veterans' Administration hospitals implemented a quality improvement project to reduce falls and falls with injury on identified large medical/surgical pilot units. (Quigley et al., 2016). All the hospitals were tertiary care facilities and five of the six hospitals were located in urban metropolitan settings. For all hospitals, 208 staff members completed the pre-quality improvement project survey and 197 participated in the post-survey. The survey measured knowledge of fall injury prevention components. A pre-survey was conducted and identified common gaps in fall prevention best practices across units. Results from the survey were used to design a fall prevention education program. A customized population-specific fall injury prevention program was designed for medical, surgical and combined units. Four educational programs were presented, one every three weeks via webinar. Once the educational sessions were completed, peer leaders for each unit were identified and given tools to support their role. Some of the tools included were a multifactorial fall risk assessment tool to identify specific fall and injury risk, lists of at high-risk medications that contribute to fall risks, and equipment such as floor mats and alarms.

Fall rates for all the participating facilities were compared; there was no statistically significant change in the fall rate from the period prior to the study and at 12 months and 18 months post. The data were provided in graph format and showed the study hospitals' fall rates remained unchanged initially at $\sim 4.0$ falls per 1000 patient days. There was a slight decrease to $\sim 3.5$ falls per 1000 patient days in the following two quarters, with a slight increase to $\sim 4.5$ falls per 1000 patient days in the fourth quarter. The authors concluded that continued improvement in fall risk assessments before and after falls to 
identify and address risk factors and underlying medical conditions such as orthostasis, delirium, incontinence, or mobility problems were future goals (Quigley et al., 2016).

\section{Long Term Care Falls Prevention Research.}

Rapp et al. (2008) studied fall prevention in nursing homes. The study was a secondary analysis of a cluster-randomized, controlled trial of residents in six nursing homes in Germany. There were 725 residents within these six facilities who participated, and of note, $80 \%$ were female. Three of the nursing homes were randomized to the intervention group and three to the control group (Rapp).

In the intervention groups, a fall prevention program consisting of education for staff and residents, environmental assessments and exercise was introduced. The environmental assessment included examining lighting, bed height and floor surfaces. Exercise was offered twice a week and focused on balance and resistance training. Fall events were recorded in all participating facilities (intervention and control) using a daily fall calendar.

During analysis, the data were further broken down into several participant subgroups, which included cognitive impairment, prior history of falls, and urinary incontinence. There was a reduction of falls within these subgroups, with those in the intervention homes showing improvement over those within the same subcategory in the control homes. Rapp et al. reported the data utilizing a hazard ratio; those in the intervention group who had some degree of cognitive impairment had a post study hazard ratio (HR) of 0.49 compared to those who had no cognitive impairment who had an HR of 0.91. Those in the intervention group who had a prior history of falls had an HR of 0.47 compared to an HR of 0.77 for those residents with no prior history of falls. The 
final subgroup was urinary incontinence; those with urinary incontinence had an HR of 0.59; those with no urinary incontinence had an HR of 0.98. (Rapp). The overall fall numbers showed a significant decrease in the intervention group, for which 428 total falls were recorded for the 12-month study period versus 771 total falls in the control group. Rapp et al. concluded that the effectiveness of a multifactorial fall prevention program differed based on the data from each subgroup, but overall that it could be helpful to allocate fall prevention resources in long term care facilities.

Neyens et al. (2009) designed a study that examined a multifactorial fall prevention program in Geri-psych nursing home residents. The study was a cluster randomized, controlled 12-month trial that took place in 12 nursing homes in The Netherlands. There were 518 participants, and based on their cognitive impairments, consent to participate was obtained from their legal guardian or power of attorney for health care. Six of the nursing homes were randomized to the intervention group and the remaining six were allocated to the control group. The only data point that was measured was total number of falls in each group during the study period. The intervention program consisted of a general medical assessment focusing on fall risk and an additional specific fall risk evaluation tool assessing fall history, medication intake, mobility and the use of assistive and protective aids. Each intervention unit was provided with a multidisciplinary fall prevention team, which included facility staff, a nursing home physician, two nurses, a physiotherapist and an occupational therapist. The interdisciplinary teams met regularly to discuss each fall event, newly admitted residents, and at the request of the unit. In the control groups, staff and unit management received 
oral and written education regarding data collection but were not given any insight or information related to the fall prevention program developed for the intervention groups.

At the end of the study period, there were 355 falls recorded for the intervention group, (2.09 falls per patient per year) and 422 falls (2.54 falls per patient per year) for the control group. The authors did not provide any pre-study data for comparison. Neyens et al. concluded that the introduction of a structured multifactorial fall prevention program did significantly decrease falls in the Geri psych population of the studied nursing homes.

\section{Health Literacy}

In addition to assessing a patient's risk for falls, it is essential to consider how the education will be received and if the patient and/or family will understand what is being taught. Health literacy is defined as the degree to which individuals have the capacity to obtain, process, and understand basic health information and services needed to make appropriate health decisions (Heinrich, 2012). It is a complex concept that is made up of various skills, including reading and writing printed materials. It may also include skills in basic math, listening, knowledge and speaking (National Institute for Health [NIH], 2016).

In a scholarly paper, Johnson (2014) commented on the impact of health literacy. Low health literacy often makes it difficult for certain demographic groups, such as the elderly or non-English speaking, to obtain the desired healthcare outcomes. Also, the level of literacy can change depending on the subject matter. Health literacy is recognized as an important component of delivering patient-centered care. However, there has been limited research about the impact of the health literacy environment on health outcomes. 
An understanding by nurses of health literacy is crucial to enhancing the involvement of their patients in their health care (Johnson).

In a follow up paper, Johnson (2015) examined more specifically strategies that nurses could utilize to create a health literate environment. Johnson stated that nurses often overestimate a patient's health literacy, as do physicians and other health care providers. The use of effective interpersonal communication between members of the health care team and the use of materials in both written and visual formats were identified as areas that could be focused on. Strategies to provide effective interpersonal communication as well as tips for personalizing health care information were provided (Johnson).

A research study by Heinrich (2012) described the concept of health literacy and how to assess it in patients with diabetes in a primary care setting. The tool utilized, the Newest Vital Sign, was designed specifically to measure health literacy in primary care settings. The sample consisted of 54 participants of various cultural backgrounds. Study participants completed a demographic survey. They were then given the Newest Vital Sign tool, which consisted of a nutritional label on a package of ice cream and six questions related to the label. If the patient was unable to read the questions, they were read to them and interpreters were available for non-English speaking patients. The tool used a 0-6 scoring method.

Two-thirds of participants $(\mathrm{n}=54)$ scored 3 or less, which indicated a strong possibility of low health literacy. Significant correlations were also identified between health literacy, educational background and ethnicity but were not reported. The average score for participants who identified as white was 4.92 on the $0-6$ scoring scale. Those 
participants who identified as either black or Hispanic/Latino scored 2.78 and 1.68 respectively. The author concluded that low health literacy is more common than most health care providers are aware of and that health literacy assessment needs to be considered in all practice settings.

Review of the literature did not identify any studies related to health literacy in long- term care.

\section{Nurses and Patient Education}

Neil (2015) discussed the responsibilities of nurses regarding patient education. She looked back to the early days of nursing, when Florence Nightingale recognized patient teaching as a function of the nurse. Neil also reviewed the American Nurses Association's view on the nurses' role in patient teaching. The ANA "supports the professional nurse's responsibility to teach the patient and family relevant facts about specific health care need" (p. 14). It was also noted that the Joint Commission stated "Patients have the right to receive appropriate education and to use the knowledge they gain to participate in decision-making" (p. 14). Neil noted Medicare's prospective payment system for patient education must include medication management, disease/ illness, and availability of support systems. The author concluded that nurses are ethically and legally responsible for the education of patients.

Bergh et al. (2013) conducted a study to measure nurses' perceptions of conditions for patient education. The focus on conditions was centered around aspects of competency. An additional aim of the study was to describe the difference in conditions for nurses working in primary, municipal, and hospital settings. The focus on conditions was centered around aspects of competency. A 47-item survey concerning factual 
experience and attitudes about patient education was sent out to 842 nurses. Eighty-three percent of the surveys were returned $(\mathrm{N}=690)$.

The nurses' perceptions differed based on which setting they practiced in. The results confirmed that the nurses perceived patient teaching to be an important responsibility. The results differed based on where the nurses worked, their use of research in patient education and their current level of education. For example, 18 of the respondents who worked in ambulatory care felt strongly that they were qualified in patient teaching compared to 17 who worked in a hospital setting and 5 who worked in primary care. The data did not indicate the education level of the respondents. Fewer than $50 \%$ of the nurses had postgraduate education and only $21 \%$ of the participants had university-based education; the majority of the nurses had obtained a diploma as their primary education. The authors concluded that management support is essential in creating a culture where patient education is deemed important and is incorporated in their daily work (Bergh et al.).

Hollis, Glgasiter, and Lapsley (2014) surveyed nurses on a general practice unit in a regional/rural hospital in New South Wales to assess nurses' knowledge level of diabetes patient education and ability to provide patient education. Data were collected utilizing a questionnaire that measured knowledge of the National Association of Diabetes Centers guidelines. Fifty-seven percent $(\mathrm{N}=29)$ of the 52 nurses employed on the general inpatient unit participated in the survey. The data, which measured nurses' knowledge of the diabetes pathophysiology, blood glucose levels and monitoring, dietary issues, and medication management, were analyzed.

The authors determined that not all nurses were prepared to provide the necessary 
education to the patient population they were focusing on. Seventy-six percent $(n=22)$ could identify an acceptable blood glucose range, $58 \%(n=17)$ were able to provide good sources of carbohydrates and $31 \%(n=9)$ could describe proper storage for insulin in use. The educational preparation of the nurses was not comprehensive and could cause a gap in education provided to the patients. This gap could adversely affect the desired patient outcomes. Identifying knowledge deficits in healthcare provider education and and patient management is the first step in tailoring an educational program for the staff. The authors concluded that this would then provide improved education to the population served (Hollis et al.).

\section{Teach-back}

The teach-back method is an evidence-based method that confirms patient understanding of health care related information taught to them by a health care professional (Tamura-Lis, 2013). The objective is to have the patient relay back to the health care professional what has been retained, in their own words. This allows the individual providing the education to assess what the patient has learned and what needs to be reinforced in later education sessions (Tamura-Lis). Since the early 2000s, the teach-back method has become standard practice for nurses to assess whether information they are providing to patients has been understood and retained (Brady, 2013; Caplin \& Saunders, 2015; Miller, 2016). As a result, research related to the use of teach-back has become evident in the literature.

In a review article by Tamura-Lis (2013), utilization of the teach-back method to improve quality education and patient safety was discussed. The teach-back method is an evidence-based approach used to ask patients to repeat, in their own words, what they 
need to know or do using a non-shaming approach. The author described in depth three components of the method: how the teach-back method can be used to promote patient health literacy; how teach-back facilitates patient comprehension; and the key elements for using the method appropriately. Tamura-Lis described an increase in health literacy especially in certain demographic groups including the elderly, the poor, minority groups, people with limited education, and people who did not speak English during early childhood after use of the teach-back method. The teach-back method provides nurses with another teaching tool to support patients faced with chronic illnesses and multiple health issues, such as the elderly. The author provides the reader with examples of two different patient education scenarios where the teach-back method is useful and examples of assessing patient understanding with such phrases as "I want to be sure I explained everything clearly, please tell me in your own words what you heard me say" (Tamura-Lis). If the patient expresses misunderstanding or is unsure of certain aspects, the nurse can rephrase the teaching in a way that may be clearer for the patient. Clinicians should avoid asking yes or no questions since they do not assess knowledge retained and a patient may be too embarrassed to say they did not understand a certain concept.

Caplin and Saunders (2015) advocated a step-by-step approach to utilizing the teach-back method to reinforce patient education. The authors observed that patients are reluctant to admit to their health care providers that they do not understand what has been taught to them. In addition, it was noted that the teach-back method may decrease the risk of not being understood by those with low health literacy, especially in situations where health literacy is not assessed. The authors recommended the use of role-play 
between colleagues to improve teaching skills and use of the teach-back method. This practice would also standardize the process and all patients will receive education that they are able to understand and retain. The authors concluded that the method is a simple but powerful tool that promotes the understanding of important information to patients as well as family members. Most importantly, it demonstrates that the information was understood (Caplin \& Saunders).

Fidyk, L., Ventura, K., \& Green, K. (2014) described the development of a curriculum for nurses on teaching patients and a portion of the education focused on the teach-back method. Teach-back is centered on the goal of incorporating a patient and family centered approach to improve communication and quality of care. The impetus behind the development of the program was the lack of educational resources to teach nurses how to teach. After a review of current literature, the decision was made to focus the education on nurses with more than six months of clinical nursing experience and utilized the principles of adult learning theory. The course contained a video component that captured real-life patient education experiences. The video was followed by a didactic component, including games to engage the participants and role-playing opportunities to practice their skills. Participants, recruited by unit leadership, were given an evaluation form at the end of the session. The nurses were asked open-ended questions regarding their perceptions and self-assessment of patient educational skills, including quality and effectiveness. The 15 participants scored the program using a 4point Likert scale (with $1=$ poor and $4=$ excellent). The average score for relevance to practice was 3.65. A 3-month post-education evaluation revealed that many of the participants $(\mathrm{n}=10)$ had followed through with their plan to provide written material to 
reinforce verbal information but only one third $(n=5)$ had followed through with the plan to refer patients and families to the education center. The authors concluded that further investigation of the teach-back method and its impact on patient satisfaction related to education and nurse communication was necessary.

A quasi-experimental study with repeated measures design was used to assess nurses' knowledge of heart failure self-care before, immediately after and three months after an educational intervention on five principles of HF self-management taught to patients using the teach-back method (Maharamus et al., 2014). The study was conducted in a large tertiary care hospital system in the Southeastern United States. A sample of 250 registered nurses who regularly cared for patients with heart failure were invited to participate in the study and 150 consented. All of the participants were from four adult inpatient units in three hospitals and the system home health department.

A competency tool was developed to determine the nurses' ability to correctly use the teach-back method when teaching self-care principles to heart failure patients. Sixty-one nurses (41\%) who participated in the program completed the pre-test, immediate post-test and three-month follow up survey. The passing score for testing was established at $>85 \%$. Of the original150 nurses, $65(\mathrm{n}=9)$ passed the pre-test and $41.3 \%$ $(n=62)$ passed the post-test given immediately after the program. At the three-month follow up test, $88.5 \%(\mathrm{n}=54)$ passed; however, the number of participants had decreased to 61 from the original 150. Also, some nurses received remediation, which may be reflected in the higher passing rate after three months. Findings from the study demonstrated the need for a comprehensive educational program for nurses on heart failure self-care principles and the teach-back method, along with regular reinforcement 
after the program. The investigators acknowledged a small sample size, in a single hospital system, limited generalizability and recommended replication.

Haney and Shepherd (2014) explored whether teaching nurses to use the teachback method to educate patients in HF self-care could reduce hospital readmissions. The authors explored the elements/process of the teach-back method. They stressed the importance of asking open-ended questions rather than yes or no questions and of beginning education as soon as the patient is medically able to receive education. The teach-back method is an educational tool that allows the teacher, in this case the nurse, to assess the patient's health literacy and determine how much of the education was understood by the patient. The goal is to have the patient repeat the information taught and thereby "teach-back" to the nurse what they learned (Haney \& Shepherd). The patient population the authors focused on was congestive heart failure patients who were readmitted within 30 days after discharge, who had two or more admissions for heart failure within the previous year, or were at risk for readmission based on their risk score.

There were 23 patients in the sample and one died prior to the completion of the study. Education sessions were scheduled with the patients who agreed to participate and met the inclusion criteria. The sessions focused on self-management in the outpatient setting, fluid balance and weight monitoring, as well as medication and follow up compliance. The sessions were performed in the teach-back format. To assess the effectiveness of the teach-back method on the readmission rate, participants' medical records were reviewed 30 days post discharge to determine if readmission had occurred. 
Of the three patients who were readmitted within the 30 days, only one was readmitted for heart failure, a 5\% reduction in the readmission rate prior to the implementation of the teach-back method. The authors concluded that the teach-back method allows nurses to fully assess what their patients understand and allows more emphasis to be placed on those areas or topics that they do not fully understand (Haney \& Shepherd).

A study conducted by Peter et al. (2015) assessed the impact of the teach-back method on the 30-day readmission rate for patients with heart failure. The study was conducted at a 951-bed tertiary care facility. The pre-study readmission rate for the study hospital was $30 \%$, significantly higher than the Medicare national average of $21 \%$. A multidisciplinary team was assembled, including nurses, nurse educators, pharmacists and other allied health professionals. The team established that a key learner must be identified and it may or may not be the patient; it may be a family member or care giver not necessarily related to the patient. The key learner would be responsible and accountable for the learning process. The nurses on the study unit were given teach-back questions to use in educating the patients regarding several components of heart failure prevention. The contents of the questions were surprising to many of the nurses, who had believed the information they were providing for their patients was clear and easy to understand. The questions given to the nurses to utilize focused on medication knowledge (What is the name of your water pill?), dietary knowledge (What foods should you avoid?), after-care (What weight gain are you to report to your physician?), and general knowledge (What are your 2 symptoms of heart failure?). The nurses on the study unit were to review the questions and correct answers with the patient initially on 
admission and then each day the questions would change slightly to assess the patient's retention of the information. The questions changed from what, to why, to how in order to assess the patient's knowledge, attitudes and behaviors.

Data on readmission for the selected population were monitored for a three-month period after the six-month pilot was completed on the study unit. The rates were reviewed again after one year and were found to have decreased $12 \%$ from the readmission rates prior to the program. The authors did not include the actual rates in the article, just the summary of findings (Peter et al.).

In a study by Miller et al. (2016), the patient perspective on the teach-back method was explored. Miller and other educators on the cardiovascular unit surveyed 30 patients who had undergone cardiac catheterizations. The goal of the survey was to develop an educational program from the patients' perspective. Once the patient education was completed, they assessed what the patient learned. Less than $50 \%$ of the patients were able to remember all that was taught to them.

The educators used the patient survey information to develop an educational program for nurses that included role-playing and stressed the value of the teach-back method. Once the nursing education was completed and implemented, the author and her colleagues evaluated another 30 patients to assess the effectiveness of the teach-back method. The feedback from the patients was positive. They appreciated the opportunity to ask questions, discuss concerns and clarity misconceptions. Feedback from the nursing staff was initially negative, in that they felt this method would require extra time for them to complete. However, after several weeks of using the method, the nurses reported they were using the teach-back method $77 \%$ of the time during patient education. In order to 
sustain the momentum, the author and her colleagues plan to regularly review patient satisfaction scores regarding education and overall satisfaction. Further evaluation to assess the patient's understanding could include patient follow up phone calls (Miller).

Next the theoretical framework guiding this project will be presented. 


\section{Theoretical Framework}

For the purpose of this quality improvement project, two theories were utilized: Benner's Skills Acquisition Theory and Kellogg's Logic Model.

\section{Benner's Skill Acquisition Theory}

In 1984, Patricia Benner published her nursing theory of skills acquisition. She based her framework on the works of Dreyfus, a mathematician and philosopher who had developed a theory of skills acquisition that Benner adapted to nursing (Benner, 1984). Benner's theory outlines five stages including novice, advanced beginner, competent, proficient, and expert. Her research demonstrated that nurses' practice grows through experiential learning and through transmitting that learning in practice settings. She went on to further expand her theory by identifying seven domains of nursing practice: helping role; teaching; monitoring; management of changing situations; interventions; quality health care practice; and organizational competency (Benner).

Each of Benner's five stages can be further explained by looking at a description of each level (1984). The novice is traditionally a beginner with no experience and has been taught general rules, have very little flexibility in their behavior and are task oriented. The advanced beginner has gained experience from prior situations and is able to recognize recurring, meaningful components and can demonstrate acceptable performance.

The third stage is referred to as competent. This is typically a nurse with two to three years of experience in the same area of practice. This nurse is able to think analytically and has set long-term goals. The nurse in the fourth stage is considered 
proficient. At this level, the practitioner sees the whole picture and uses this knowledge to drive decision-making and is able to modify plans and knows what to expect in certain situations. The final stage is the expert. This nurse has an intuitive grasp of clinical situations, performance is fluid and efficient and has flexibility and much more background experience (Benner).

Nurses and other health care practitioners can move between these stages at any point in their career (Benner, 1984). For example, a nurse who changes area of specialty may move from expert to novice as new skills are learned. Conversely, a novice nurse may be an expert in computerized documentation while a more experienced nurse functions at the novice level when documenting on the computer.

In 1997, Gary Rolfe revisited Benner's theory and made several non-clinical references to explain Benner's theory to those out of the health care arena. His primary focus was on the expert practitioner. He uses examples of driving a car or playing the piano to illustrate those performing at the expert level. These tasks, when functioning as an expert, are done without conscious thought, as a nurse who is functioning at the expert level cares for her patients fluidly, almost without conscious thought of her actions.

Rolfe (1997) challenged Benner's title of expert and suggested that as nursing moved toward a more evidence-based model, and nurses were constantly acquiring knowledge, the stage should be referred to as reflexive practitioner. His rationale was that unlike the expert, the reflexive practitioner is able to justify clinical decisions and provide reasoned arguments for acting in a certain manner. In contrast, the expert, in Benner's theory cannot always justify actions.

As nurses are educated in utilizing the teach-back method, they will experience 
being novices again, regardless of their years of experience or current level of expertise in caring for residents. Through continued use of the teach-back method, it is anticipated that the nurses will gain confidence in using this method it's use and progress toward the level of expert described by Benner.

\section{Logic Model Development Guide}

The Kellogg Logic Model Development Guide (Kellogg, 2004) uses a road map design to assist in developing a plan that places events in sequence to achieve the desired outcome. The model uses a five-step process, as illustrated in Figure 1 below.

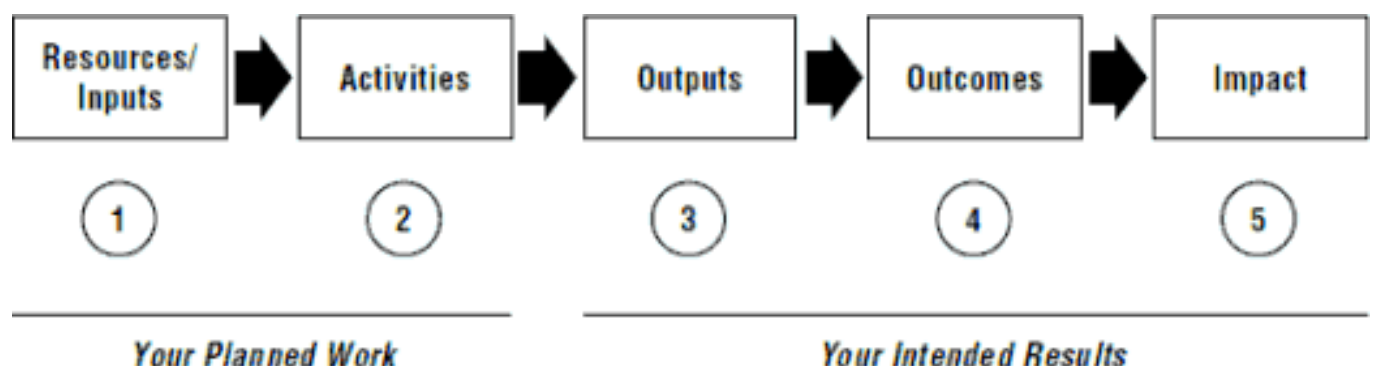

Figure 1. The Basic Logic Model.

The first step, input, assess the resources needed to develop the program. The second step is activities or what is needed to be done in order for those individuals or groups to accomplish the short-term outcomes to be achieved (Kellogg, 2004).

The final three steps of the Kellogg Logic Model are designed to assist in producing the intended results. The outputs are the product of the activities step; for example, the educational plan and objectives are developed and delivered to the intended audience. Outcomes are a result of changes in practice that occur from the education received. Lastly, the impact of the whole process reflects the desired outcomes achieved and what was the impact overall. 
The design of the model allows for movement both forward and backwards in the steps. The model suggests that users plan backwards, meaning set your ultimate goal before determining what resources are needed. Once the goals have been set, the user implements the plan forward, toward that ultimate goal (Kellogg, 2004). The Logic Model will provide guidelines to assist in program development and in identifying measurable outcomes.

Next, the method will be outlined. 


\section{Method}

\section{Purpose}

The purpose of this quality improvement project was to develop a program to increase the staff nurses' knowledge and confidence using the teach-back method to teach fall prevention strategies to residents in a long-term care facility.

\section{Design}

The design was a quality improvement project, with development of a program about the teach-back method.

\section{Sample and Site}

The project took place in a 170-bed family owned long term care facility that provides care to skilled and non-skilled residents. The sample included licensed nursing staff (both RN and LPN) working at this facility. The education sessions were offered twice during regularly scheduled education time for staff development.

\section{Background}

Beginning in 2017, CMS began requiring long-term care facilities to develop quality improvement programs targeting several areas, including falls and fall prevention (CMS, 2017). The majority of long-term care facilities have fall prevention strategies in place, but have not developed them into a formal quality improvement initiative. There is little current research regarding fall prevention programs in post-acute care settings. There is also a lack of research looking at the use of the teach-back method in long-term care facilities. 


\section{Program Development}

Resources/Input. Nurses at a small family owned long-term care facility had little to no exposure to the teach-back method. Many of the staff had been nurses for greater than 10 years and were not introduced to the teach-back method during their education. The newer nurses have been taught the process of the teach-back method, but based on the level of education (Associate degree, diploma, or Bachelor's degree) the content of the education varied. There had also been an increase in the number of falls within the last quarter of $9 \%$. This scenario provided an opportunity to increase the nursing staffs' knowledge of the teach-back method and confidence in using the method to educate residents and their families about fall prevention interventions available at the facility.

The increase in falls was discussed at the quarterly quality improvement meeting, which is attended by the director of nursing, the facility administrator and the medical director. When there is a significant change in a quality measure, planning for quality improvement project occurs. At this particular meeting, not only was the increased number of falls noted, but the discussion regarding CMS changes to use of bed and chair alarms was also mentioned. With an increase in the number of falls with alarms in use, the group began to brainstorm to develop a plan to decrease the numbers of falls, while decreasing the numbers of bed and chair alarms in use to be compliant with CMS regulations.

It was noted during the discussion that there was very little education provided to residents on admission about fall prevention and increased safety awareness. All residents, for example, are educated on the use of the call light, but there is no return 
demonstration to assess level of understanding. The discussion then led to supporting this quality improvement project that would potentially increase residents' awareness of their own safety and assess the level of comprehension by having the resident return demonstrate or teach-back to the staff what was told to them. The nurses were educated on the process of the teach-back method and were able to practice the process with scripted scenarios aimed at increasing knowledge and confidence in using the teach-back method with their residents on admission and discharge

Activities/Procedures. Permission to conduct the project had been obtained from the facility's director of nursing, fall prevention coordinator, and staff education coordinator. Dedicated education time was secured, as the facility has scheduled education/in-service hours each month. Attendance was voluntary. Rhode Island College IRB approval was obtained prior to beginning the quality improvement project.

An educational power point presentation was developed while IRB review was pending and date and times for the education was secured with the director of nursing and the staff education coordinator. Once IRB approval had been obtained, an informational letter (Appendix A) describing the education was made available for staff to review prior to the education sessions. An informational poster (Appendix B) was posted throughout the facility to give staff the opportunity to view the date and times that the educational session was going to be offered. Since the sessions were not mandatory, it was unclear how many participants would attend.

The educational session began with a review of what the teach-back method is, why the teach-back method was developed and the evidence that supports the use of the teach-back method. Statistical data was presented to demonstrate the impact falls have in 
health care. This was followed by a review of the fall prevention tools available at the facility, including low beds, bed/chair alarms, and non-skid slippers. The power point concluded with a sample teach-back scenario, including scripting of a teach-back session. The 30-minute educational session included an opportunity for the participants to roleplay a scenario using the teach-back method

Outputs. The educational power point was developed utilizing the objectives and content outline summarized below (Table 1). The session was designed to last 30 minutes, so the staff would be able to attend during work time and objectives would be met utilizing the content identified. The history of the teach-back method, the impact of falls in healthcare and the tools available for staff were highlighted. The opportunity to practice the teach-back method was encouraged at the end of each session to assist the staff in increasing their confidence in using the method.

\section{Table 1}

Content Outline and Objectives

\begin{tabular}{|l|l|l|}
\hline \multicolumn{1}{|c|}{ Content } & \multicolumn{1}{|c|}{$\begin{array}{c}\text { Objective of the } \\
\text { Content }\end{array}$} & \multicolumn{1}{c|}{ Time Frame } \\
\hline $\begin{array}{l}\text { Evidence based } \\
\text { description of the teach- } \\
\text { back method }\end{array}$ & $\begin{array}{l}\text { To review the history of } \\
\text { the teach-back method }\end{array}$ & 10 minutes \\
\hline $\begin{array}{l}\text { Statistical fall data and } \\
\text { impact on healthcare }\end{array}$ & $\begin{array}{l}\text { To discuss the impact of } \\
\text { falls in the acute and } \\
\text { post-acute care setting }\end{array}$ & 5 minutes \\
\hline $\begin{array}{l}\text { Listed fall prevention } \\
\text { tools and strategies }\end{array}$ & $\begin{array}{l}\text { To describe the fall } \\
\text { prevention resources } \\
\text { available at the facility }\end{array}$ & 5 minutes \\
\hline $\begin{array}{l}\text { Sample teach-back } \\
\text { scenario and role-playing }\end{array}$ & $\begin{array}{l}\text { To practice using the } \\
\text { teach-back method }\end{array}$ & 10 minutes \\
\hline
\end{tabular}


Outcomes/Measurement. A pre-test/post-test survey was adapted from a survey developed by Mahramus et al. (2014) to measure nurses' perceptions of conditions for patient education. The questions were modified slightly by changing the wording to capture the perceptions of nurses' confidence with utilizing the teach-back method for patient education. A copy of the pre-test/post-test can be found in Appendix C. There was no demographic information collected; however, to compare pre and post-test results, the participants were asked to provide their mother's date of birth. Prior to the initial session, the content and pre/post-test were piloted with 1-2 staff members to assess the measurement tool.

A brief evaluation (Appendix D) was also provided to the participants to determine if the nurses felt that the education increased their knowledge of the teachback method and if they would utilize the method in their nursing practice.

Impact/evaluation. Once the sessions were completed, aggregate and individual data of the pre and post-test scores were compared to gauge improved confidence in utilizing the teach-back method. The desired outcome of the quality improvement project was an increase in nurses' knowledge and confidence utilizing the teach-back method for conceptual materials. A long-term measurable outcome would be a decrease in the numbers of falls, this can be monitored later and was not within the scope of this quality improvement project.

The facility's director of nursing expressed support and interest in the project as well as the results. Potential barriers to this quality improvement project include the unwillingness of nurses to participate in the voluntary educational session or their unwillingness to utilize the teach-back method. Since the sessions were open to all 
nurses, regardless of years of experience, age, gender or ethnicity, no other concerns were identified.

Next the results will be discussed. 


\section{Results}

There were 36 potential participants who could have attended either of the educational sessions offered. Of the 36 , six nurses were on medical leave of absence or vacation during the time frame. This lowered the potential number of participants to 30 . Of those remaining who were eligible to participate, 10 nurses attended the sessions $(33 \%)$.

The pre and post-test survey consisted of four questions designed to assess the learners' knowledge and understanding of the teach-back method, their preparedness to teach fall prevention education, if they used the teach-back method on a consistent basis to teach fall prevention education and whether the teach-back method was practical to use when teaching fall prevention strategies. The tests were scored with a 5-point Likert scale. The responses were weighted from 1-5 with agree having a weight of 1 and disagree a weight of 5 . Mean scores were calculated for each question and compared. Table 2 on the next page demonstrates the results of the pre-test. 
Table 2

Pre-Test Results by Number of Respondents $(N=10)$

\begin{tabular}{|c|c|c|c|c|}
\hline \multicolumn{5}{|c|}{$\begin{array}{l}\text { A. I understand how to use the teach-back method to teach and assess resident's } \\
\text { knowledge of fall prevention education }\end{array}$} \\
\hline $\begin{array}{l}\text { Agree } \\
(1)\end{array}$ & $\begin{array}{l}\text { Somewhat } \\
\text { agree } \\
(2)\end{array}$ & $\begin{array}{c}\text { Neither agree } \\
\text { or disagree } \\
\text { (3) }\end{array}$ & $\begin{array}{l}\text { Somewhat } \\
\text { disagree } \\
\text { (4) }\end{array}$ & $\begin{array}{l}\text { Disagree } \\
\quad(5)\end{array}$ \\
\hline 3 & 2 & 3 & 1 & 1 \\
\hline \multicolumn{5}{|c|}{ B. I am prepared to teach fall prevention education } \\
\hline $\begin{array}{l}\text { Agree } \\
\text { (1) }\end{array}$ & $\begin{array}{l}\text { Somewhat } \\
\text { agree } \\
(2)\end{array}$ & $\begin{array}{c}\text { Neither agree } \\
\text { or disagree } \\
(3)\end{array}$ & $\begin{array}{c}\text { Somewhat } \\
\text { disagree } \\
(4)\end{array}$ & $\begin{array}{l}\text { Disagree } \\
\quad(5)\end{array}$ \\
\hline 3 & 5 & 1 & 0 & 1 \\
\hline \multicolumn{5}{|c|}{$\begin{array}{l}\text { C. I use the teach-back method on a consistent basis when I teach residents fall } \\
\text { prevention strategies }\end{array}$} \\
\hline $\begin{array}{l}\text { Agree } \\
\text { (1) }\end{array}$ & $\begin{array}{l}\text { Somewhat } \\
\text { agree } \\
(2)\end{array}$ & $\begin{array}{c}\text { Neither agree } \\
\text { or disagree } \\
(3)\end{array}$ & $\begin{array}{c}\text { Somewhat } \\
\text { disagree } \\
(4)\end{array}$ & $\begin{array}{l}\text { Disagree } \\
\quad(5)\end{array}$ \\
\hline 2 & 4 & 3 & 0 & 1 \\
\hline \multicolumn{5}{|c|}{$\begin{array}{l}\text { D. The teach-back method is not practical when teaching residents fall prevention } \\
\text { strategies }\end{array}$} \\
\hline $\begin{array}{l}\text { Agree } \\
(5)\end{array}$ & $\begin{array}{l}\text { Somewhat } \\
\text { agree } \\
(4)\end{array}$ & $\begin{array}{c}\text { Neither agree } \\
\text { or disagree } \\
(3)\end{array}$ & $\begin{array}{l}\text { Somewhat } \\
\text { disagree } \\
(2)\end{array}$ & $\begin{array}{l}\text { Disagree } \\
\quad(1)\end{array}$ \\
\hline 0 & 4 & 2 & 1 & 3 \\
\hline
\end{tabular}

Results of the pre-test indicate that $30 \%(n=3)$ understood how to use the teachback method prior to receiving the education provided. Twenty percent $(n=2)$ had some understanding of how to use the method and 30\% $(n=3)$ neither agreed nor disagreed with the question. When asked if they felt prepared to use the teach back method, $40 \%(n=4)$ of the nurses felt they were somewhat prepared to use the teach-back method prior to the presentation and role-playing opportunity. Forty percent $(n=4)$ of the respondents felt that the teach-back method was somewhat impractical to use when teaching fall prevention strategies. 
The mean response score for the four questions respectively were $2.5,2.1,2.4$, and 2.7, indicating the participants had somewhat of an understanding of the teach-back method and how it could be used as a practical method for teaching fall prevention strategies.

After the educational power point and role-playing session completed, the posttest was given to the participants. The questions in the post-test were identical to the questions in the pre-test with the exception of question 3. The wording of question 3 was modified slightly to reflect the potential change in practice using the teach-back method.

Table 3 illustrates the responses from the post-test.

Table 3

Post-Test Results by Number of Respondents $(N=10)$

A. I understand how to use the teach-back method to teach and assess resident's knowledge of fall prevention education

\begin{tabular}{|c|c|c|c|c|}
\hline $\begin{array}{c}\text { Agree } \\
(1)\end{array}$ & $\begin{array}{c}\text { Somewhat } \\
\text { agree } \\
(2)\end{array}$ & $\begin{array}{c}\text { Neither agree } \\
\text { or disagree } \\
(3)\end{array}$ & $\begin{array}{c}\text { Somewhat } \\
\text { disagree } \\
(4)\end{array}$ & $\begin{array}{c}\text { Disagree } \\
(5)\end{array}$ \\
\hline 9 & 1 & 0 & 0 & 0 \\
\hline
\end{tabular}

B. I am prepared to teach fall prevention education

\begin{tabular}{|c|c|c|c|c|}
\hline $\begin{array}{c}\text { Agree } \\
(1)\end{array}$ & $\begin{array}{c}\text { Somewhat } \\
\text { agree } \\
(2)\end{array}$ & $\begin{array}{c}\text { Neither agree } \\
\text { or disagree } \\
(3)\end{array}$ & $\begin{array}{c}\text { Somewhat } \\
\text { disagree } \\
(4)\end{array}$ & $\begin{array}{c}\text { Disagree } \\
(5)\end{array}$ \\
\hline 9 & 1 & 0 & 0 & 0 \\
\hline
\end{tabular}

C. I will use the teach-back method on a consistent basis when I teach residents fall prevention strategies

\begin{tabular}{|c|c|c|c|c|}
\hline $\begin{array}{c}\text { Agree } \\
(1)\end{array}$ & $\begin{array}{c}\text { Somewhat } \\
\text { agree } \\
(2)\end{array}$ & $\begin{array}{c}\text { Neither agree } \\
\text { or disagree } \\
(3)\end{array}$ & $\begin{array}{c}\text { Somewhat } \\
\text { disagree } \\
(4)\end{array}$ & $\begin{array}{c}\text { Disagree } \\
(5)\end{array}$ \\
\hline 9 & 0 & 1 & 0 & 0 \\
\hline
\end{tabular}

D. The teach-back method is not practical when teaching residents fall prevention strategies

\begin{tabular}{|c|c|c|c|c|}
\hline $\begin{array}{c}\text { Agree } \\
(5)\end{array}$ & $\begin{array}{c}\text { Somewhat } \\
\text { agree } \\
(4)\end{array}$ & $\begin{array}{c}\text { Neither agree } \\
\text { or disagree } \\
(3)\end{array}$ & $\begin{array}{c}\text { Somewhat } \\
\text { disagree } \\
(2)\end{array}$ & $\begin{array}{c}\text { Disagree } \\
(1)\end{array}$ \\
\hline 0 & 1 & 1 & 0 & 8 \\
\hline
\end{tabular}


The post education results indicated that $90 \%(n=9)$ now understood how to use the teach-back method to educate residents and how the method would assist them is assessing the residents' knowledge of the fall prevention strategies available at the facility. Ninety percent of the nurses indicated that after the presentation and roleplaying session, they felt completely prepared to teach fall prevention strategies to their residents.

When asked if they would use the teach-back method on a consistent basis when educating residents on fall prevention, $90 \%(n=9)$ agreed that this would now become part of their practice. Finally, $80 \%$ of the participants felt that the teach-back method was practical when teaching something more conceptual, like fall prevention strategies.

The mean scores for the post-test questions were also calculated and compared to the pre-test means. The average score by question were $1.1,1.1,1.2$ and 1.5 respectively. Mean scores were increased on every question. The post-test scores indicated that the objectives were met: the nurses agreed that their knowledge of the teach-back method had increased, they felt prepared to use the method and that the method was practical to use.

The post-test also included a short evaluation of the educational session to gauge the usefulness of the presentation overall and to determine if it had met the needs of the participants. Table 4 on the next page illustrates the responses to these questions. 
Table 4

Post Education Evaluation Questions by Number of Respondents $(N=10)$

\begin{tabular}{|c|c|c|c|c|}
\hline \multicolumn{5}{|c|}{$\begin{array}{l}\text { The education program I attended today increased my knowledge and confidence in } \\
\text { using the teach-back method for resident fall prevention education. }\end{array}$} \\
\hline $\begin{array}{c}\text { Agree } \\
\text { (1) }\end{array}$ & $\begin{array}{c}\text { Somewhat } \\
\text { agree } \\
\text { (2) }\end{array}$ & $\begin{array}{c}\text { Neither agree } \\
\text { or disagree } \\
(3)\end{array}$ & $\begin{array}{c}\text { Somewhat } \\
\text { disagree } \\
\text { (4) }\end{array}$ & $\begin{array}{c}\text { Disagree } \\
(5)\end{array}$ \\
\hline 9 & 1 & 0 & 0 & 0 \\
\hline \multicolumn{5}{|c|}{ I will use the teach-back method for resident education. } \\
\hline $\begin{array}{c}\text { Agree } \\
\text { (1) }\end{array}$ & $\begin{array}{c}\text { Somewhat } \\
\text { agree } \\
(2)\end{array}$ & $\begin{array}{c}\text { Neither agree } \\
\text { or disagree } \\
(3)\end{array}$ & $\begin{array}{c}\text { Somewhat } \\
\text { disagree } \\
(4)\end{array}$ & $\begin{array}{c}\text { Disagree } \\
(5)\end{array}$ \\
\hline 10 & 0 & 0 & 0 & 0 \\
\hline \multicolumn{5}{|c|}{ This presentation is useful to my nursing practice. } \\
\hline $\begin{array}{c}\text { Agree } \\
(1)\end{array}$ & $\begin{array}{c}\text { Somewhat } \\
\text { agree } \\
\text { (2) }\end{array}$ & $\begin{array}{c}\text { Neither agree } \\
\text { or disagree } \\
\text { (3) }\end{array}$ & $\begin{array}{c}\text { Somewhat } \\
\text { disagree } \\
\text { (4) }\end{array}$ & $\begin{array}{c}\text { Disagree } \\
\text { (5) }\end{array}$ \\
\hline 9 & 1 & 0 & 0 & 0 \\
\hline
\end{tabular}

The overall response rate was $90 \%$ of the nurses agreed that the program increased their knowledge and confidence in using the teach-back method for fall prevention education. One hundred percent of the nurses indicated that they will use the teach-back method for resident education. The mean scores of the post education evaluation questions were $1.1,1$, and 1.1 respectively, indicating that the nurses who participated found value in the education and time spent attending the session.

Next, the summary and conclusions will be discussed. 


\section{Summary and Conclusions}

Falls in the frail elderly often have consequences that impact their quality of life. Post fall, residents may develop an enhanced fear of falling that can lead to self-imposed limitations on activity (Taylor et al., 2005). The goal of facility-based fall prevention programs is to decrease falls and increase quality of life for the residents. The Joint Commission has identified a national patient safety goal focusing on reducing the risk of falls and harm associated with falls in long-term care facilities (Joint Commission, 2018).

The majority of fall prevention programs rely on the bedside nurse to provide written and/or verbal education to the resident and family on fall risk and fall prevention. Nurses working in the long-term care facility where the quality improvement project took place provided the education but had no method to determine whether the education provided to the residents had been retained.

The teach-back method is an evidence-based method that confirms patient understanding of materials taught to them by a health care professional (Tamura-Lis, 2013). Nurses working in long-term care have a variety of educational backgrounds and may not have been educated on the teach-back method (Hollis et al., 2014). The teachback method has been utilized in acute care but there was very little evidence found supporting the use of this method in long-term care.

The Centers for Medicare and Medicaid (CMS, 2017) recently began requiring long-term care facilities to develop quality improvement programs aimed at decreasing falls and other health care acquired conditions. As a fall prevention program was being developed in a small, family owned long-term care facility, there was discussion surrounding the resident education component and how this education would be 
provided. The teach-back method was mentioned as a way to provide the education and measure how well the information was received and retained by the residents.

A quality improvement project was developed, utilizing Benner's skills acquisition theory and Kellogg's Logic Model, to increase nurses' knowledge and confidence using the teach-back method to provide fall prevention education to the residents had. An educational power point describing the teach-back method was developed and a scenario was provided to allow the participants the opportunity to practice the teach-back method. Pre and post-tests were completed to determine the nurses' knowledge of the teach-back method and to determine if the teach-back method would be used to teach fall prevention strategies.

Thirty-three percent $(\mathrm{N}=10)$ of eligible nurses participated in the educational sessions that were offered. After the education and role-playing sessions were completed, $90 \%(n=9)$ of the participants agreed that they understood what the teachback method was. The post-test revealed that $80 \%(n=8)$ of the nurses felt that the teachback method was practical for teaching fall prevention to the residents. The post education evaluation indicated that $90 \%(n=9)$ of the nurses felt that their knowledge and confidence in using the teach-back method to teach fall prevention strategies had improved. Ninety percent $(n=9)$ of the respondents also indicated that the education was useful to their nursing practice.

The scope of the project was limited by the number of participants. Less than half of the eligible nurses participated in the sessions offered. With such a small number of participants, the author would suggest offering the educational sessions again and add the teach-back education to new hire orientation. Another limitation identified was there was 
only one day offered to provide the education. The education coordinator had previously scheduled in-services and was only able to accommodate this educational session on one day.

In conclusion, the educational sessions did meet the goal of increasing nurses' knowledge and confidence in using the teach-back method in a long-term care setting. The teach-back method was a useful tool in this setting and $100 \%$ of the nurses indicated that they would use the teach-back method for resident education.

Next, recommendations and implications for advanced nursing practice will be discussed next. 


\section{Recommendations and Implications for Advanced Nursing Practice}

The Advanced Practice Registered Nurse (APRN) has the knowledge and skills necessary to assist in identifying, developing, and implementing quality improvement and educational programs based on evidence-based practice. The APRN can take the lead in these projects and enhance the knowledge base of nursing staff. By assisting nurses to keep current, the patients or residents will potentially benefit from the practice changes the education can bring.

This quality improvement project utilized Benner's skills acquisition theory. The APRN is an excellent resource for nurses at any stage of Benner's theory and can assist the nurses in transitioning through each stage. As nurses learn new skills or increase competence in known skills, the APRN can provide evidence-based resources to improve outcomes.

A gap in knowledge was addressed by the development of education to increase knowledge and confidence in a teaching method, the teach-back method. This method benefits the patient by increasing awareness of fall prevention education, the nurse by providing a way to assess the education they are providing, and the facility by enhancing the fall prevention program under development to meet CMS and Joint Commission requirements. The recommendation of including this education in new hire orientation will be presented to the Director of Nursing. By continuing to offer this education, the nurses' confidence in using the teach-back method should continue to increase, thereby increasing the quality of education provided to the residents. 
Advanced Practice Registered Nurses, specifically Clinical Nurse Specialists

(CNSs), are valuable assets to any health care setting. They are experts in their specialty and have the ability to identify areas for improvement that benefit the patient, nurse, and system. By moving seamlessly through the spheres of practice, the CNS is a leader who can facilitate change. As a leader, the APRN can demonstrate leadership in meetings and at the bedside.

As a leader at the bedside, the APRN can ensure nursing practice stays current and also introduce evidence-based practice to nurses of all levels of expertise. In a systems setting, the APRN can lead interdisciplinary teams focused on practice change and policy development. The APRN can then facilitate the dissemination of information and provide leadership and guidance through these processes.

With the increase focus by regulatory agencies on fall prevention in long-term care, there should be greater emphasis on developing national polices that focus on these programs and their intended outcomes. Through participation in national organizations, the CNS could be instrumental in the development of such policies. By incorporating elements of the teach-back method into these programs, nurses in long-term care would be better able to asses and reinforce needed components of the education. The APRN would be instrumental in developing policies that support the use of the teach-back method for education that supports the decrease in falls in nursing care centers.

There is a definite need for more research surrounding fall prevention programs in long-term care facilities and the use of the teach-back method. This was evident during the development of this quality improvement project. Much of the research done in longterm care focusing on fall prevention programs was done greater than 12 years ago. 
Advanced Practice Registered Nurses can guide new research and provide a review of current evidence-based literature to support the process. Guidelines developed for fall prevention programs from this research could be shared nationally with other similar facilities to improve outcomes and regulatory compliance. 


\section{References}

Benner, P. (1984). From novice to expert: excellence and power in clinical nursing practice. Menlo Park: Addison-Wesley.

Bergh, A., Persson, E., Karlsson, J., \& Friberg, F. (2014). Registered nurses' perceptions of conditions for patient education - focusing on aspects of competence. Scandinavian Journal of Caring Sciences, 28(3), 523-536. doi:10.1111/scs.12077

Brady, A. (2013). Educating nurses about educating patients: mind your words. Oncology Nurse Advisor. March/April: 46-47.

Cangany, M., Back, D., Hamilton-Kelly, T., Altman, M., \& Lacey, S. (2015). Bedside nurses leading the way for falls prevention: an evidence-based approach. Critical Care Nurse, 35(2), 82-84 3p. doi:10.4037/ccn2015414

Caplin, M., \& Saunders, T. (2015). Utilizing teach-back to reinforce patient education. Orthopaedic Nursing, 34(6), 365-368 4p. doi:10.1097/NOR.0000000000000197

Centers for Medicare and Medicaid (2016 a). Hospital-acquired conditions. Retrieved from: www.cms.gov/medicare/medicare-fee-for-service payment/hospitalacqcond/hospital-acquired_conditions.html

Centers for Medicare and Medicaid (2016 b). Nursing home data compendium 2015 edition. Retrieved from: https://www.cms.gov/Medicare/Provider-EnrollmentandCertification/CertificationandComplianc/Downloads/nursinghomedatacompen dium_508-2015.pdf

Centers for Medicare and Medicaid (2017) Nursing home quality initiatives. Retrieved from: https://www.cms.gov/Medicare/Quality-Initiatives-Patient-AssessmentInstruments/NursingHomeQualityInits/index.html 
Coyle, R. (2016). Initiating and sustaining a fall prevention program. Nursing, 46(5), 1621 5p. doi:10.1097/01.NURSE.0000482277.72036.50

Fidyk, L., Ventura, K., \& Green, K. (2014). Teaching nurses how to teach. Journal for Nurses in Professional Development, 30(5), 248-253.

doi:10.1097/NND.0000000000000074

Haney, M., \& Shepherd, J. (2014). Can teach-back reduce hospital readmissions? American Nurse Today, 9(3), 50-52

Heinrich, C. (2012). Health literacy: the sixth vital sign. Journal of the American Academy of Nurse Practitioners, 24(4), 218-223. doi:10.1111/j.17457599.2012.00698.

Hollis, M., Glaister, K., \& Lapsley, J. A. (2014). Do practice nurses have the knowledge to provide diabetes self-management education? Contemporary Nurse: A Journal for the Australian Nursing Profession, 46(2), 234-241

Institute for Healthcare Improvement (2017). Fall prevention. Retrieved from: http://www.ihi.org/Topics/Falls/Pages/default.aspx

Johnson, A. (2014). Health literacy, does it make a difference? Australian Journal of Advanced Nursing, 31(3), 39-45 7p.

Johnson, A. (2015). Health literacy: how nurses can make a difference. Australian Journal of Advanced Nursing, 33(2), 20-27 8p.

Joint Commission (2017). 2017 National patient safety goal presentation. Retrieved from: www.jointcommission.org/npsg_presentation/

Joint Commission (2018). Nursing care center national patient safety goals. Retrieved from: www.jointcommission.org/assets/1/6/2018_NCC_NPSG_goals_final.pdf 
Mahramus, T., Penoyer, D. A., Frewin, S., Chamberlain, L., Wilson, D., \& Sole, M. L. (2014). Assessment of an educational intervention on nurses' knowledge and retention of heart failure self-care principles and the teach back method. Heart \& Lung, 43(3), 204-212. doi:10.1016/j.hrtlng.2013.11.012

Miller, S. (2016). "Teach-back" from a patient's perspective. Nursing, 46(2), 63-64 2p. doi:10.1097/01.NURSE.0000476249.18503.f5

National Institutes of Health (2016). Health literacy. Retrieved from: www.nih.gov/institutes-nih/nih-office-director/office-communications-publicliaison/clear-communication/health-literacy

National Quality Forum (2012). Falls screening, risk assessment, and plans of care to prevent future falls. Retrieved from: www.qualityfourm.org/workarea/linkit.aspx.

Neil, H. P. (2015). Patient education: are nurses legally responsible? MedSurg Nursing, 24(6), S14-S14.

Neyens, J. C., Dijcks, B. P., Twisk, J., Schols, J. M., Van Haastregt, J. C., van den Heuvel, W. J., \& de Witte, L. P. (2009). A multifactorial intervention for the prevention of falls in psychogeriatric nursing home patients, a randomized controlled trial (RCT). Age and Ageing, 38(2), 194-199

Peter, D., Robinson, P., Jordan, M., Lawrence, S., Casey, K., \& Salas-Lopez, D. (2015). Reducing readmissions using teach-back. Journal of Nursing Administration, 45(1), 35-42 8p. doi:10.1097/NNA.0000000000000155

Quigley, P. A., Barnett, S. D., Bulat, T., \& Friedman, Y. (2016). Reducing falls and fallrelated injuries in medical-surgical units. Journal of Nursing Care Quality, 31(2), 139-145 7p. doi:10.1097/NCQ.0000000000000151 
Rapp, K., Lamb, S. E., Büchele, G., Lall, R., Lindemann, U., \& Becker, C. (2008). Prevention of falls in nursing homes: subgroup analyses of a randomized fall prevention trial. Journal of the American Geriatrics Society, 56(6), 1092-1097

Robinovitch, S. N., Feldman, F., Yang, Y., Schonnop, R., Leung, P. M., Sarraf, T., \& Loughin, M. (2013). Video capture of the circumstances of falls in elderly people residing in long-term care: an observational study. The Lancet, 381(9860), 47-54.

Rolfe, G. (1997). Beyond expertise: theory, practice and the reflexive practitioner. Journal of Clinical Nursing, 6(2), 93-97.

Rubenstein, L.Z. (2006). Falls in older people: epidemiology, risk factors and strategies for prevention. Age and Aging 37(41), 35-52. doi: 10.1093/aging/afl084.

Staggs, V. S., Davidson, J., Dunton, N., \& Crosser, B. (2015). Challenges in defining and categorizing falls on diverse unit types: lessons from expansion of the NDNQI Falls Indicator. Journal of nursing care quality, 30(2), 106.

Tamura-Lis, W. (2013). Teach-back for quality education and patient safety. Urologic Nursing, 33(6), 267-298. doi:10.7257/1053-816X.2013.33.6.267

Taylor, J. A., Parmelee, P., Brown, H., \& Ouslander, J. (2005). The falls management program: a quality improvement initiative for nursing facilities. Agency for Health Care Research and Quality (AHRQ). \#290-00-0011, Task Order No. 3. Retrieved from: www.ahrq.gov/professionals/systems/long-termcare/resources/injuries/fallspx/index.html

Trepanier, S., \& Hilsenbeck, J. (2014). A hospital system approach at decreasing falls with injuries and cost. Nursing Economics, 32(3), 135-141 7p 
Tzeng, H., \& Yin, C. (2014). Most and least helpful aspects of fall prevention education to prevent injurious falls: a qualitative study on nurses' perspectives. Journal of Clinical Nursing, 23(17/18), 2676-2680 5p. doi:10.1111/jocn.12295

Tzeng, H., \& Yin, C. (2015). Patient engagement in hospital fall prevention. Nursing Economic\$, 33(6), 326-334.

Urquhart Wilbert, W. (2013). The effectiveness of a fall prevention/management program in reducing patient falls: a retrospective study. JOCEPS: The Journal of Chi Eta Phi Sorority, 57(1), 24-27 4p.

W.K. Kellogg Foundation. (2004, January). Logic model development guide [Guideline model]. Retrieved from: www.wkkf.orgwww.CMS.gov. 


\section{Appendix A}

\section{Dear Nurses,}

On February $27^{\text {th }}$ at $12: 30 \mathrm{pm}$ and $2: 30 \mathrm{pm}$ I will be presenting an educational session about using the teach-back method to educate our residents about the fall prevention program and resources, we have available here at The Holiday. I am conducting this as the educator and as part of the requirements for completing the MSN program at RIC. This project is being done in conjunction with Dr. Cindy Padula, major project advisor.

If you choose to attend this voluntary session will last approximately one half hour. First, you will be asked to complete a brief pre-test to assess your knowledge and confidence with using the teach-back method. The brief presentation will provide details related to the teach-back method and outline the fall prevention strategies we use here at The Holiday. Each session will conclude with the opportunity to role-play a scenario using the teach-back method. A brief post-test and an evaluation of the inservice will be provided at the end of the session. You will be asked to provide your mother's date of birth on the pre- and post-tests so that scores can be compared. Your responses to the test and the evaluation survey will remain anonymous and confidential.

If you have any questions or concerns about this in-service, you may contact me at the email below or Dr. Cindy Padula at cpadula@,ric.edu. Thank you for your consideration in participating in this session.

Christine Nichols, BSN, RN

cnichols_2798@email.ric.edu 


\begin{abstract}
Appendix B
In-Service: Increasing Nurses Knowledge and Confidence Using the Teach-Back Method to Teach Fall Prevention Strategies
\end{abstract}

When: Tuesday February $27^{\text {th }}$ at

$12: 30 \mathrm{pm}$ and $2: 30 \mathrm{pm}$

Where: Upstairs Education Room

Who: Licensed Nurses

Questions? See Christine Nichols, who is conducting this in-service.

This is a voluntary in-service that is being conducted as part of the MSN program requirements at RIC. This project is being done under the direction of Dr. Cindy Padula, the project advisor.

Please consider attending! 


\section{Appendix C}

Mother's date of birth

\section{Teach-Back Method}

Please take a few minutes to answer the following questions regarding your knowledge and confidence utilizing the teach-back method for resident education.

Choose the answer that best describes you.

A. I understand how to use the teach-back method to teach and assess resident's knowledge of the fall prevention education 1-Agree 2-Somewhat agree 3-Neither agree or disagree 4-Somewhat disagree 5-Disagree B. I am prepared to teach fall prevention education 1-Agree 2-Somewhat agree 3-Neither agree or disagree 4-Somewhat disagree 5-Disagree

C. I use the teach-back method on a consistent basis when I teach residents fall prevention strategies

1-Agree 2-Somewhat agree 3-Neither agree or disagree 4-Somewhat disagree 5-Disagree

D. The teach-back method is not practical when teaching residents fall prevention strategies

1-Agree 2-Somewhat agree 3-Neither agree or disagree 4-Somewhat disagree 5-Disagree 


\title{
Appendix D
}

\author{
Evaluation
}

A. The education program I attended today increased my knowledge and confidence in using the teach-back method for resident fall prevention education.

1-Agree 2-Somewhat agree 3-Neither agree or disagree 4-Somewhat disagree 5-Disagree

B. I will use the teach-back method for resident education

1-Agree 2-Somewhat agree 3-Neither agree or disagree 4- Somewhat disagree 5-Disagree

C. This presentation is useful to my nursing practice

1-Agree 2-Somewhat agree 3-Neither agree or disagree 4-Somewhat disagree 5-Disagree 